\title{
The multi-scale spatial variance of soil moisture in the semi-arid Loess Plateau of China
}

\author{
Xueling Yao • Bojie Fu • Yihe Lü • Ruiying Chang • \\ Shuai Wang $\cdot$ Yafeng Wang $\cdot$ Changhong Su
}

Received: 6 November 2011 / Accepted: 6 February 2012 / Published online: 7 March 2012

(C) Springer-Verlag 2012

\begin{abstract}
Purpose An understanding of soil moisture heterogeneity across spatial scales has been considered to be critical to eco-hydrological research and particularly important for vegetation restoration in semi-arid areas. This study aimed to investigate the spatial variance of deep soil moisture at multiple scales in the semi-arid Loess Plateau of China. The relative importance of the related factors and the dominant driver of soil desiccation were especially discussed.

Materials and methods The impact factors in this study are related to slope positions, land use types and precipitation. To understand the relative importance of these factors to soil moisture, the experiment was conducted at three spatial scales (slope, small catchment and region) according to the impact scope of each factor. The soil moisture to a depth of $4 \mathrm{~m}$ had been obtained by in situ sampling in nine catchments along the precipitation gradients from south to north across the semiarid area of the Loess Plateau. The terrain, soil and vegetation properties were investigated synchronously. The common characteristics of soil moisture spatial variance were extracted by comparing the soil moisture profile in the plots/catchments with different climate and terrain properties.

Results and discussion At slope scale, the deep soil moisture $(>100 \mathrm{~cm})$ was heterogeneous in grasslands, while relatively homogeneous in planted shrub/forest lands. At
\end{abstract}

Responsible editor: Ying Ouyang

$\mathrm{X}$. Yao $\cdot$ B. Fu $(\bowtie) \cdot$ Y. Lü $\cdot$ R. Chang $\cdot$ S. Wang $\cdot$ Y. Wang $\cdot$ C. Su

State Key Laboratory of Urban and Regional Ecology, Research

Center for Eco-Environmental Sciences,

Chinese Academy of Sciences,

Beijing 100085, People's Republic of China

e-mail: bfu@rcees.ac.cn

B. $\mathrm{Fu}$

e-mail: bfu@mail.rcees.ac.cn catchment scale, the influence of slope position on soil moisture was not significant compared with the influence of land use types. The deep soil moisture difference between slope positions was less than $4 \%$ in grasslands and less than $1.5 \%$ in planted shrub/forest lands, while reaching $9.7 \%$ between land use types. In the catchments, the soil moisture of different land use types commonly ranked as farmland $>$ grassland $>$ planted forest land, despite the climate difference in each catchment. At regional scale, precipitation was a significant factor influencing soil moisture spatial variance, but the influence was rather slow compared with the influence of afforestation.

Conclusions The land use type was the dominant factor of soil moisture spatial heterogeneity, rather than the slope positions and precipitation change. The afforestation was the major driver of soil desiccation in the semi-arid Loess Plateau of China. In consideration of the soil moisture conservation and the vegetation sustainable development, we suggested that abandoning slope farmland to natural grassland was a more effective measure for ecological recovery in the semi-arid Loess Plateau of China.

Keywords Factor · Loess Plateau $\cdot$ Scale $\cdot$ Soil moisture $\cdot$ Spatial variation

\section{Introduction}

Soil moisture is a fundamental property affecting plant growth, transport and transformation of soil nutrients, and water and energy budgets in the soil-plant system. The spatial variation of soil moisture has important implications for all of these processes (Ersahin and Brohi 2006).

Soil moisture varies greatly across space and time based on different soil properties (Timm et al. 2006), topographic 
features (Western et al. 1999; Yeh and Eltahir 1998; Ali et al. 2010), vegetation characteristics (Gomez-Plaza et al. 2001; McLaren et al. 2001; Miyamoto et al. 2003) and atmospheric dynamics (Ramos and Mulligan 2005; Teuling et al. 2007). From the past research, soil moisture measurements are available only at a very fine scale (at in situ monitoring facilities, e.g., gravimetric sampling or time domain reflectrometry) or at a very coarse scale (by remote sensing retrieval) on a regular basis (Das et al. 2010). Because in situ measurements are cost-intensive and timeintensive, the remote sensing methods were greatly relied on for the estimation of soil moisture in fields at larger spatial scales (Joshi and Mohanty 2010). Many multi-scale soil moisture studies have been conducted with the aid of a modeling approach to bridge the gap between in situ measurements and remote sensing methods (Das et al. 2010; Brocca et al. 2010; Fu et al. 2011).

However, research on a large spatial scale based on remote sensing methods is difficult to be applied to the study of deep soil moisture because the remote sensing technology can only be used to derive the soil moisture characteristics at the surface (Zribi et al. 2003). The Loess Plateau of China, characterized by expansive loess, has a vast soil reservoir more than $50 \mathrm{~m}$ in depth (Zhu et al. 1983), which influences the surface-atmosphere water interaction and vegetation growth. In recent decades, many researchers found that desiccation widely occurs in deep soil across the whole Loess Plateau and is especially severe in arid and semiarid regions, threatening the vegetation restoration practices (Chen et al. 2008a; Shangguan 2007). Therefore, more and more concerns have been focused on the changes in deep soil water availability and the driving factors for those changes (Wang et al. 2009b; Liu et al. 2010). Because of the limits of remote sensing technology for obtaining deep soil moisture, most studies of the deep soil moisture in the Loess Plateau were based on ground measurements and conducted at catchment scale. These studies mainly focused on the temporal and spatial variation of deep soil moisture and its relation to soil properties, terrain properties (Bi et al. 2008; Qiu et al. 2001) and land use types (Wang et al. 2009b, 2011; Zeng et al. 2011; Chen et al. 2007; Fu et al. 2003) as well as on the spatial interpolation of soil water content (Wang et al. 2010a).

At a regional scale, previous studies about deep soil water in the Loess Plateau were not sufficient. Wang et al. (2004) had surveyed the deep soil water in planted Robinia pseudoacacia forest lands across nine counties in the north of Shaanxi Province and classified the drought soil into four typical zones according to the degree of dryness. Chen et al. (2004) had compared the soil moisture difference between planted forest and natural vegetation in three vegetation zones in north Shaanxi. Wang et al. (2010a) had sampled widely across the entire Loess Plateau to address the spatial variations in dried soil layer thickness and formation depth and analyzed the relationship of those variations with topography, land use types, rainfall, soil types and other factors.

At a field scale, the past research into the spatial characteristics of soil moisture was mainly related to the upper 100 cm depth, by dense sampling and geostatistical methods to study the spatial interpolation of soil water content in a plot (Yun et al. 2010). It is impractical to sample densely in a plot when investigating deep soil moisture, because deep sampling is both difficult and destructive to experimental plots. Thus, field scale research of the spatial characteristics of deep soil moisture is rare.

In the past studies, geostatistical techniques were the most popular method to characterize the spatial patterns of soil moisture and the relation to controlling factors (Bi et al. 2009; Wang et al. 2001; Zhao and Shao 2010). Additionally, linear regression models, principal component analysis and orthogonal function analysis (EOF) were widely used to identify the factors controlling soil water variation (Qiu et al. 2010; Bi et al. 2008).

In light of the past efforts, the assessment of soil moisture at different spatial scales is a key challenge because of the nonlinear dependence of soil moisture dynamics on geophysical parameters such as soil type, vegetation, topography and atmospheric forcings. At small scales (field or small watershed), soil moisture variability is greatly influenced by the interaction between soil, vegetation and topography (Grayson et al. 1997). At large scale (regional), soil moisture spatial pattern is dominated by precipitation and radiative forcings (Li et al. 2009; Das et al. 2010). Therefore, to identify the relative importance of individual factors, studies should be conducted over multiple spatial scales.

We investigated the spatial pattern of deep soil moisture and associated physical controls at multiple scales (slope, small catchment and region) in a semi-arid hydroclimatic region of the north-central Loess Plateau, China. Our objectives were to better understand the spatial variance of soil moisture on different scales and to identify the relative importance of controlling factors. The results would be beneficial to understand the causes of soil desiccation in semi-arid region of the Loess Plateau and provide valuable information for plant restoration and land management practices.

\section{Methods}

\subsection{Study plots}

The experiment was conducted in the north-central Loess Plateau of northern Shaanxi Province, China $\left(36.1^{\circ}-39.4^{\circ} \mathrm{N}\right.$, $\left.109.1^{\circ}-111.1^{\circ} \mathrm{W}\right)$, characterized by semi-arid climate and hill-gully terrain with sandy and loam soils. 
Yang et al. (1994) had divided the whole Loess Plateau into six eco-hydrological zones based on the integrated analysis of soil water background, precipitation, evapotranspiration and soil water balance. The soil water balance was based on the change of soil moisture in $200 \mathrm{~cm}$ soil depth, depending upon whether the soil water content could reach or near the field capacity after the wet season. In zone I, the soil moisture in 200 $\mathrm{cm}$ depth could reach the field capacity at end of the wet season. In zone II, only the upper $100 \mathrm{~cm}$ soil moisture probably reaches the field capacity. From zone III to zone VI the soil moisture could hardly reach the field capacity throughout the year. We had investigated nine catchments in different ecohydrological zones along the precipitation gradients (Table 1).

In the southern semi-equilibrated zone, Renjiatai, Yangou and Baijiachuan catchments were investigated. In this zone, the annual average air temperature was $9.0-9.2^{\circ} \mathrm{C}$, accumulated temperature above $10^{\circ} \mathrm{C}$ was $3000-3500^{\circ} \mathrm{C}$, annual rainfall was $510-550 \mathrm{~mm}$, annual water surface evaporation was 1400-1900 mm, local soil was dark loessial soil of medium loam, and field capacity and wilting moisture were $22 \%$ and $9 \%$, respectively.

In the periodic soil moisture deficit zone, Zhifanggou, Pingqiao and Jiuyuangou catchments were investigated. In this zone, the annual average air temperature was $6.1-8.8^{\circ} \mathrm{C}$, accumulated temperature above $10^{\circ} \mathrm{C}$ was $2000-3000^{\circ} \mathrm{C}$, annual rainfall was $400-500 \mathrm{~mm}$, local soil was cultivated loessial soil of light loam, and field capacity and wilting moisture were $19 \%$ and $5 \%$, respectively.

In the low soil moisture loss zone, Jinfuping, Liudaogou and Huangfu catchments were investigated. In this zone, the annual average air temperature was $7.3^{\circ} \mathrm{C}$, accumulated temperature above $10^{\circ} \mathrm{C}$ was $2000-3200^{\circ} \mathrm{C}$, annual rainfall was $350-400 \mathrm{~mm}$, annual water surface evaporation was 1700-2500 mm, local soil was cultivated loessial soil of sandy loam, and field capacity and wilting moisture were $17 \%$ and $4.5 \%$, respectively.
Within each of the nine catchments, four typical land use types were chosen, including slope farmland, abandoned farmland covered with natural grasses, planted Robinia pseudoacacia forest land and planted Caragana korshinskii or seabuckthorn shrub land. The area of each plot was $10 \mathrm{~m} \times 20 \mathrm{~m}$. All the forest/shrub lands and grasslands used to be slope farmlands before they were planted or abandoned. The residual unconverted slope farmlands had been cultivated for over 50 years, with the major crops being corn, soybeans and millet. The environmental characteristics of each catchment are shown in Table 1. The positions of the catchments are shown in Fig. 1.

\subsection{Field measurements}

The soil moisture measurement was conducted in July and August 2009 and July 2010. During this period, each plot was measured for one time in our experiment. Within each plot, three spatial replicates were taken along the slope. One or two additional spatial replicates were taken for the natural grasslands according to our experience that the soil moisture variation was more noticeable in the grassland, which will be discussed subsequently. Within each plot, the sampling points were distributed along the slope with about $10-\mathrm{m}$ intervals.

The soil samples were extracted using a soil auger with $20 \mathrm{~cm}$ intervals down the soil profile to a depth of $400 \mathrm{~cm}$. Once extracted from the ground, the samples were placed in aluminum cans with tight-fitting lids, and the gravimetric water content (GWC) was determined from the weight loss after oven drying at $105^{\circ} \mathrm{C}$ to a constant mass. The soil bulk density (BD) was measured synchronously in each plot using ring-cut. Then the volumetric water content (VWC) was calculated by multiplying the GWC and the $\mathrm{BD}$ and dropping the units.

Table 1 The characteristics of the eco-hydrological zones

\begin{tabular}{|c|c|c|c|c|}
\hline Vegetation zones & Heat zones & Soil water ecological zones & Catchments & Precipitation $(\mathrm{mm})$ \\
\hline Broad-leaf forest & Warm temperate zone & I Balanced soil water compensation zone & & $600-750$ \\
\hline \multirow[t]{2}{*}{ Forest grassland } & \multirow[t]{2}{*}{ Warm temperate zone } & \multirow[t]{2}{*}{ II Semi-equilibrium soil water compensation zone } & $\begin{array}{l}\text { Renjiatai } \\
\text { Yangou }\end{array}$ & \multirow[t]{2}{*}{$510-550$} \\
\hline & & & Baijiachuan & \\
\hline \multirow[t]{7}{*}{ Typical grassland } & \multirow[t]{7}{*}{ Warm temperate-temperate zone } & \multirow[t]{3}{*}{ III Periodic soil water deficit zone } & Zhifanggou & \multirow[t]{3}{*}{$400-500$} \\
\hline & & & Pingqiao & \\
\hline & & & Jiuyuangou & \\
\hline & & \multirow[t]{3}{*}{ IV Low soil water loss zone } & Jinfuping & \multirow[t]{3}{*}{$350-400$} \\
\hline & & & Liudaogou & \\
\hline & & & Huangfu & \\
\hline & & V Unbalanced soil water cycle zone & & $250-350$ \\
\hline Desert grassland & Temperate zone & VI Intense soil water cycle deficit zone & & $<250$ \\
\hline
\end{tabular}


Fig. 1 The distribution of the investigated catchments

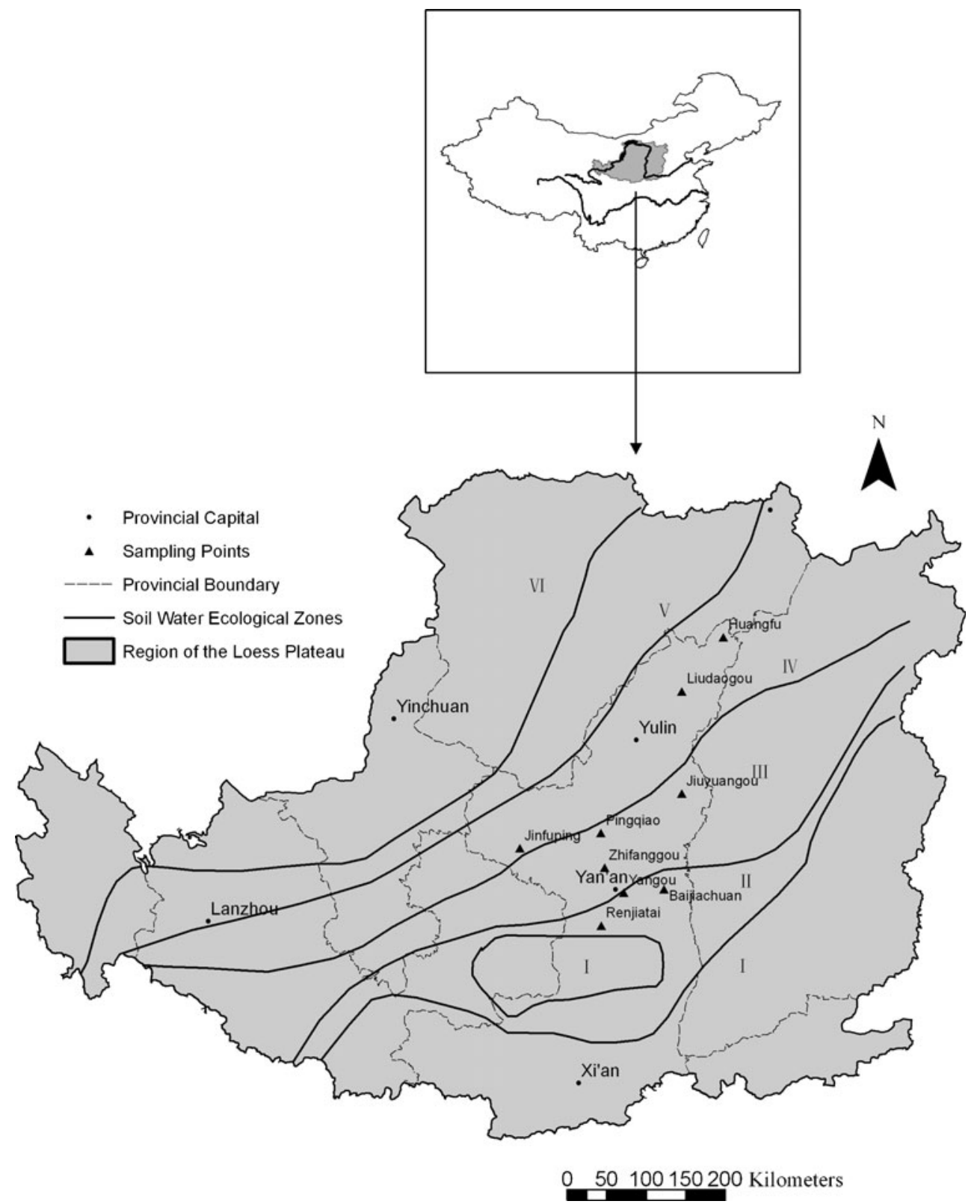

In field, we used a GPS receiver with 5-m precision to obtain the altitude, longitude and latitude, which were later imported into a geographic information system (Arc/Info) as Albers coordinates. The slope's degree and aspect were measured with a geological compass. The land use types, primary soil types and vegetation species and coverage (\%) were estimated by observation. The restoration years of each site were obtained from local people familiar with the site's history. A part of the soil samples were conserved to examine the soil texture using a laser diffraction size analyzer (Mastersizer 2000, Malvern Instruments Limited, Worcestershire, UK) in laboratory. To avoid the effect of soil properties difference, several plots with unusual soil texture were excluded from this study. The soil texture involved in this study was mainly loessial sandy loam soil with the silt particles being $65-75 \%$ and bulk density being $1.2-1.4 \mathrm{~g} / \mathrm{cm}^{3}$ according to laboratory measurements.

\subsection{Experimental design and statistical methods}

At slope scale, three land use types, including natural grassland, planted shrub land and planted forest land, were selected to characterize the spatial variation of soil moisture within a plot (Table 2). The statistic range (the difference between the lowest and highest values) was used to measure the soil moisture difference between slope positions. The larger the range, the lower probability that the soil moisture 
Table 2 The details of the plots and the soil moisture ranges within each plot

\begin{tabular}{|c|c|c|c|c|c|c|c|}
\hline \multirow[t]{2}{*}{ Land use types } & \multirow[t]{2}{*}{ Location } & \multirow[t]{2}{*}{ Dominant species } & \multirow{2}{*}{$\begin{array}{l}\text { Growth } \\
\text { years }\end{array}$} & \multirow{2}{*}{$\begin{array}{l}\text { Slope } \\
\text { aspect }\end{array}$} & \multirow[t]{2}{*}{ Gradient } & \multicolumn{2}{|l|}{ Range (\%) } \\
\hline & & & & & & $20-80 \mathrm{~cm}$ & $80-400 \mathrm{~cm}$ \\
\hline Grassland 1 & Renjiatai & Lespedeza davurica, Artemisia vestita & 20 & South & 8 & 1.8 & 3.2 \\
\hline Grassland 2 & Zhifanggou & Bothriochloa ischaemum, Artemisia vestita & 20 & Southwest & 31 & 2.2 & 5.6 \\
\hline Grassland 2 & Zhifanggou & Artemisia vestita, Lespedeza davurica & 16 & North & 33 & 1.1 & 3.1 \\
\hline Planted shrub land 1 & Jinfuping & Hippophae reamnoides & 10 & Southwest & 21 & 2.1 & 0.9 \\
\hline Planted shrub land 2 & Jinfuping & Hippophae reamnoides & 8 & Northeast & 25 & 1.0 & 0.7 \\
\hline Planted shrub land 3 & Zhifanggou & Caragana korshinskii & 16 & North & 33 & 3.3 & 1.5 \\
\hline Planted forest land 1 & Zhifanggou & Robinia pseudoacacia & 26 & South & 27 & 3.0 & 0.8 \\
\hline Planted forest land 2 & Zhifanggou & Robinia pseudoacacia & 33 & Northeast & 33 & 4.1 & 2.2 \\
\hline Planted forest land 3 & Renjiatai & Robinia pseudoacacia & 25 & Northeast & 8 & 1.6 & 1.2 \\
\hline
\end{tabular}

at any one position could represent the average condition of the whole plot.

At small catchment scale, to analyze the influence of land use types on soil moisture, six catchments were chosen to compare the soil moisture between slope farmland, natural grassland and planted $R$. pseudoacacia forest land. The grasslands had been restored over 10 years, and the planted $R$. pseudoacacia forest lands had been restored over 20 years. In each catchment, the three types of land use are located on comparable slopes with similar gradient (about $20^{\circ}$ ) and aspect (Table 3).

In semi-arid regions of the Loess Plateau, soil moisture strongly depends on the precipitation. At regional scale, in each ecological zone, three plots of slope farmlands, grasslands and planted forest lands with similar terrain and soil properties were selected to compare the soil moisture various along the precipitation gradients. The average soil moisture of each land use types in each zone was calculated. The annual precipitation of each catchment was estimated using Kriging's interpolation method based on the monthly precipitation data from 1951 to 2009 from 81 weather stations in the Loess Plateau. The data were downloaded from the

Table 3 The average soil moisture content of various land use types in each catchment

Catchments Slope Average soil moisture content aspect $(\%)(20-400 \mathrm{~cm})$

Farmland Grassland Forest land Range (\%)

\begin{tabular}{llrrrr}
\hline Renjiatai & North & 23.4 & 17.8 & 10.5 & 12.9 \\
Yangou & South & 17.8 & 12.9 & 7.6 & 10.2 \\
Zhifanggou & South & 16.0 & 13.5 & 7.4 & 8.6 \\
Pingqiao & South & 12.1 & 9.7 & 5.2 & 6.9 \\
Jiuyuangou & North & 15.4 & 6.8 & 4.7 & 10.7 \\
Huangfu & North & 12.4 & 9.3 & 3.8 & 8.6 \\
\hline
\end{tabular}

Loess Plateau Data Sharing and Server Center (http://loess. geodata.cn/Portal/index.jsp).

The field measurements had lasted more than 1 month. During this period, several light rainfalls $(<10 \mathrm{~mm})$ occurred in some catchments. Because the influence depth of light rainfalls on soil moisture was generally considered not beyond $60 \mathrm{~cm}$ in the Loess Plateau ( $\mathrm{Li}$ et al. 2006), we ignored the upper $100 \mathrm{~cm}$ soil moisture data to make sure that the influence of rainfalls had been excluded when comparing the soil moisture at regional scale. The soil moisture below $100 \mathrm{~cm}$ depth had been proved fairly stable in certain time scale in case of no heavy or continuous rains (Li et al. 2006; Wang et al. 2010a). And the soil moisture below $200 \mathrm{~cm}$ may keep unchanged for many years (Wang et al. 2009b). This is the reason why we focused our experiment on the spatial variation and concerned less about the temporal variation of deep soil moisture in this study.

Partial correlations were used to evaluate the degree of the association of the soil moisture and related factors at regional scale.

Excel 2003 and SPSS 13.0 were used to perform statistical analyses, and Origin 7.5 was used to draw diagrams. ArcGIS 9.2 was used to produce the maps.

\section{Results}

3.1 Soil moisture characteristics at a slope scale

In $20-80 \mathrm{~cm}$ soil layer, the range of soil moisture between slope positions was $1.7 \%$ in grassland, $2.9 \%$ in planted forest land and $2.1 \%$ in planted shrub land (Fig. 2). The soil moisture lateral variance was more obvious in planted forest/shrub lands than that in natural grasslands in this layer. In $100-400 \mathrm{~cm}$ soil layer, the corresponding ranges were $4.0 \%, 1.4 \%$ and $1.0 \%$, respectively. The soil moisture lateral variance was significant in grasslands but relatively obscure 
Fig. 2 Soil moisture profile characteristics of different land use types at slope scale
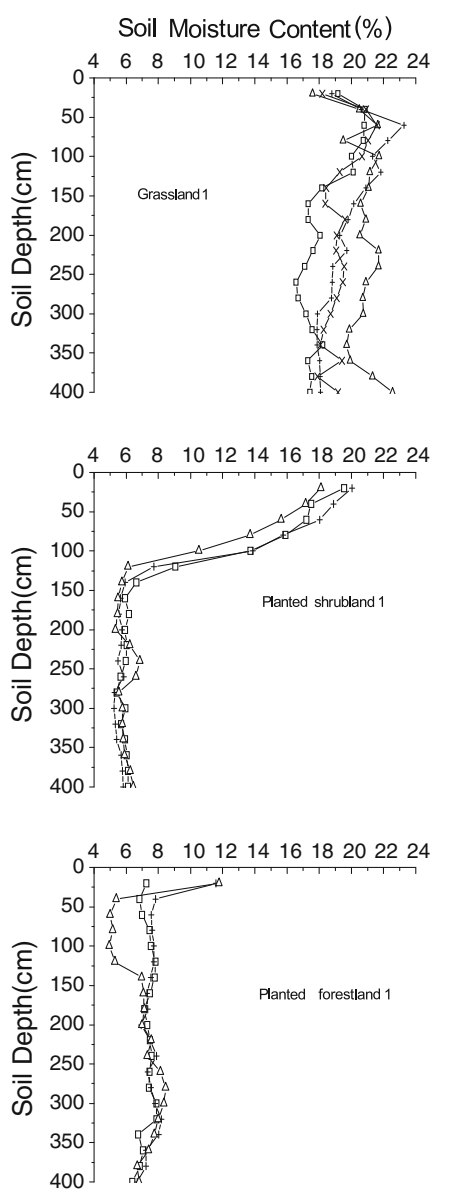
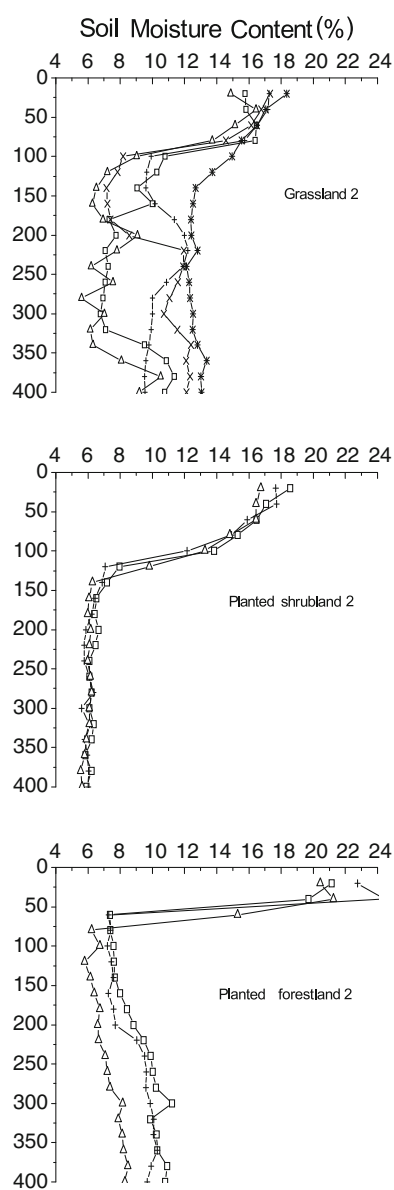

Soil Moisture Content $(\%)$
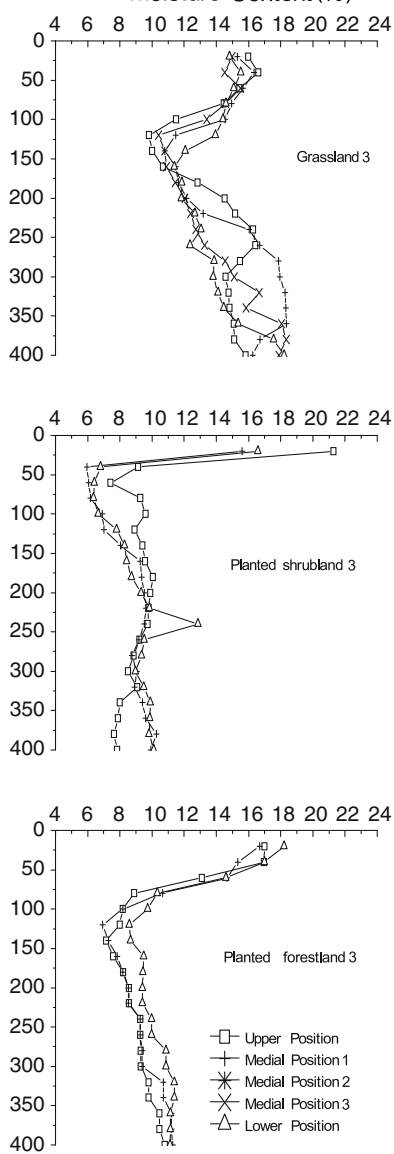

in planted forest/shrub lands in this layer. Moreover, the significant variance commonly existed in grasslands, no matter whether the average soil moisture of the plot was higher (grassland 1) or lower (grassland 2). Comparatively, the soil moisture in 100-400 cm depth was generally low and homogeneous in planted forest/shrub lands, with the average soil moisture being 6-9\%. In addition, the soil moisture in lower positions was not always higher than that in upper positions in the nine plots in Fig. 2. Actually, we did not find any correlation between soil moisture and slope positions in all the land use types in our investigation.

\subsection{Soil moisture characteristics at a catchment scale}

Figure 3 displays the soil moisture profile characteristics of different land use types at small catchment scale. In farm land, the soil moisture content ranged from 12.1 to $23.4 \%$ in the six catchments, with the average value being $16.2 \%$ (see Table 3). In grasslands, the soil moisture content ranged from 6.8 to $17.8 \%$, with the average value being $11.7 \%$. In planted R. pseudoacacia forest land, the soil moisture content ranged from 3.8 to $10.5 \%$, with the average value being $6.5 \%$. In all the six catchments, the common trend of soil moisture content was farmland $>$ natural grassland $>$ planted forest land, despite the different climate background and ante-precipitation in each catchment. This means that this trend commonly existed and was relatively stable regardless of the climate difference in a catchment. The deep soil water content $(>100 \mathrm{~cm})$ of planted forest land was close to $9 \%$ in Renjiatai catchments, 5\% in Yangou and Zhifanggou catchments and 4\% in Pingqiao, Jiuyuangou and Huangfu catchments, which all neared the local wilting point (see Fig. 3). The soil moisture of grassland was significantly different in different catchments, but always lower than that of farmland and higher than that of forest lands. In some cases (such as Zhifanggou and Huangfu catchments), the soil moisture of grasslands was lower than that in farmland in the upper $200 \mathrm{~cm}$ soil, but close to it in the $200-400 \mathrm{~cm}$ soil. This result corresponds to the study by Wang et al. (2009a), who indicated that the soil moisture depletion depth was about $200 \mathrm{~cm}$ in natural grassland.

\subsection{Soil moisture characteristics at a regional scale}

At regional scale, the partial correlation coefficients between soil moisture and precipitation, slope gradient, slope aspect and restoration years were calculated for different land use types (Table 4). The precipitation and soil moisture showed significantly positive correlation in grassland and shrub/forest land, with the correlation coefficient over 0.8 . However, the correlation was not significant in farmland. 
Fig. 3 Soil moisture profile characteristics of different land use types at small catchment scale
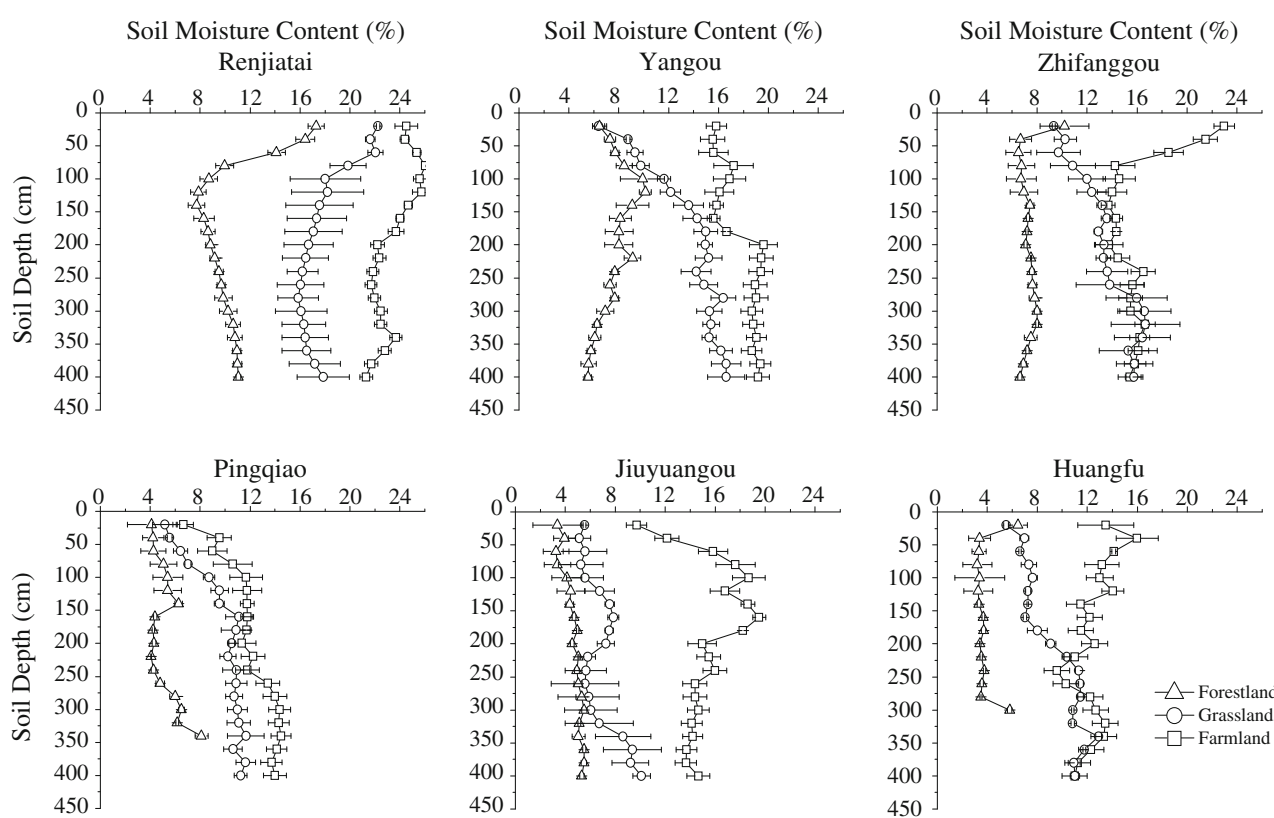

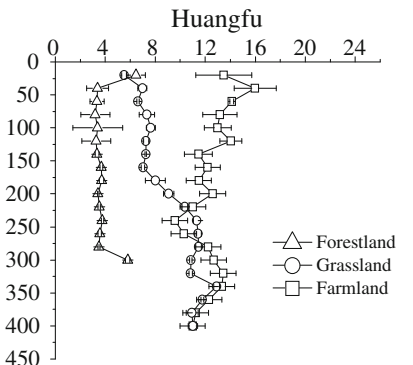

The correlation between slope gradient/aspect and soil moisture was not significant for all the land use types. This means that they are not the main factors impacting soil moisture at regional scale. The restoration years and soil moisture were negatively correlated in planted forest land $(r=-0.55, p<0.05)$, but not significantly correlated in the other land use types. Based on this result, only the planted forests with about 20 years were chosen to compare with other land use types in the other section of this study.

From the results we conclude that precipitation was the major factor impacting soil moisture compared with the other related factors at regional scale.

Additionally, several comparable plots were selected in different eco-hydrological zones to display the soil moisture change along the precipitation gradients. The results showed that the soil moisture content generally decreased with decreasing regional precipitation for the three land use types (Fig. 4). From zone II to zone IV, the annual precipitation decreased about $188 \mathrm{~mm}$, while the soil moisture decreased about $3 \%$ in farmland, $4 \%$ in grassland and $5 \%$ in planted forest land.

Table 4 The partial correlations between soil moisture and the related factors

\begin{tabular}{lcccc}
\hline Land use types & $\begin{array}{l}\text { Farmland } \\
(N=7)\end{array}$ & $\begin{array}{l}\text { Grassland } \\
(N=13)\end{array}$ & $\begin{array}{l}\text { Shrub land } \\
(N=9)\end{array}$ & $\begin{array}{l}\text { Forest land } \\
(N=21)\end{array}$ \\
\hline Precipitation & 0.056 & $0.812^{\mathrm{b}}$ & $0.809^{\mathrm{a}}$ & $0.809^{\mathrm{b}}$ \\
Gradient & 0.369 & 0.048 & 0.368 & -0.223 \\
Slope aspect & -0.479 & -0.133 & -0.404 & 0.116 \\
Restoration years & - & -0.377 & -0.735 & $-0.550^{\mathrm{a}}$ \\
\hline
\end{tabular}

$N$ is the available sample numbers

${ }^{\text {a }}$ Correlation is significant at the 0.05 level (2-tailed)

${ }^{\mathrm{b}}$ Correlation is significant at the 0.01 level (2-tailed)

\section{Discussion}

Because the dense sampling of deep soil would severely damage experiment plots, the research on deep soil moisture spatial heterogeneity at slope scale was rare. Thus, little is known about the spatial heterogeneity of deep soil moisture within a plot. In previous studies, many researchers tried to reduce the spatial sampling replicates to decrease the workload and the damage to experiment plots as possible, ignoring the heterogeneity of soil moisture in different land use types. The number of sampling replications was always subjectively decided and apportioned equally in all land use types in their studies (Wang et al. 2010b, 2008, 2009a; Ren et al. 2010). This study revealed the heterogeneity of deep soil moisture in different land use types at slope scale and provided primary reference for apportioning spatial

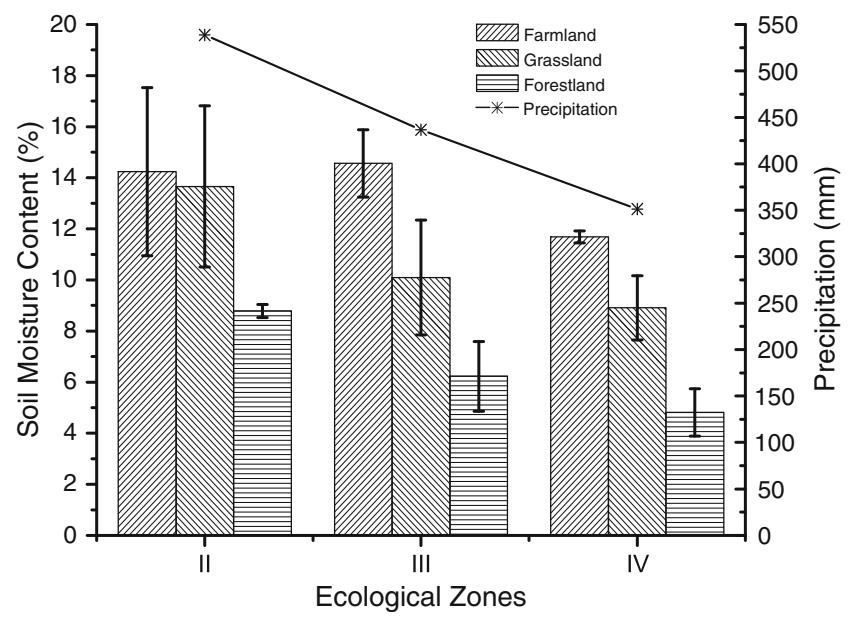

Fig. 4 The average soil moisture of different land use types in each ecological zone 
replications among different land use types to balance the study accuracy and the workload.

In the grasslands, the soil moisture was relatively homogeneous in $20-80 \mathrm{~cm}$ soil layer but rather heterogeneous in $100-400 \mathrm{~cm}$ soil layer within a plot. This means that the soil moisture at any one position could hardly represent the general condition of the whole plot. On the contrary, in the planted forest/shrub lands, the soil moisture profile was uniform at different slope positions, especially below a depth of $100 \mathrm{~cm}$. It is well acknowledged that root-soil interaction tends to equalize soil water content in the root zone (Das et al. 2010; Ivanov et al. 2010; Mohanty et al. 2008). The homogenization effect of vegetation could diminish the spatial heterogeneity caused by local topography (Vivoni et al. 2007; Hawley et al. 1983). And this homogenization effect was particularly obvious in the planted forests, which were characterized by deep roots, simple community composition and uniform age structure. Furthermore, although the plots (see Fig. 2) were located in different catchments with different climate backgrounds and terrain properties (see Table 2), the slope-scale soil moisture spatial characteristics were similar for the same land use type. This means that these slope-scale characteristics of soil moisture may commonly exist, regardless of the difference of climate and terrain. Thus, we suggest that more spatial replicates should be taken in the grassland when studying deep soil moisture $(>80 \mathrm{~cm})$ and that more spatial replicates should be taken in the planted forest land when studying shallow soil moisture $(<80 \mathrm{~cm})$ in semi-arid area of the Loess Plateau.

In all the investigated catchments, the soil moisture difference between land use types was rather significant. The ranges of soil moisture between land use types reached 6.9$12.9 \%$ in the six catchments (see Table 3). In contrast, the ranges between different slope positions were less than $3 \%$ in $20-80 \mathrm{~cm}$ depth and less than $4 \%$ in $100-400 \mathrm{~cm}$ depth (see Table 2). Therefore, we conclude that the difference of land use types induced higher spatial soil moisture heterogeneity than slope position in the Loess Plateau of China.

The grasslands and forest/shrub lands used to be slope farmlands before they were abandoned or planted, which were similar to the current unconverted farmlands in this study. If all the farmlands had not been converted, the soil moisture in similar slopes should be similar. Thus, the current significant difference of soil moisture between similar slopes should be mainly caused by the difference of the restored vegetation. From this study, the grassland had decreased $2.4-5.6 \%$ soil water content, while the planted forest land had decreased $6.9-12.9 \%$ compared with the unconverted farmland. And all of these happened in less than 30 years.

Precipitation difference does impact soil moisture significantly as we analyzed at regional scale. However, the precipitation change is a rather slow process at time scale, and even getting a definite changing trend needs hundreds of years ( $\mathrm{Lu} 2009)$. The soil moisture decrease was only $3-$ $5 \%$ when the precipitation decreases about $188 \mathrm{~mm}$. It is rather gentle compared with the influence of vegetation.

The drivers of soil desiccation in the Loess Plateau had been a research focus, but the dominant drivers have still not been determined clearly. Some researchers considered that climate drying was a major driver of soil desiccation (Yang et al. 1999; Li and Shao 2001), while others thought that inappropriate afforestation was the major driver (Li 2001). Yang et al. (1999) found that the degree of soil desiccation closely depends on the regional precipitation. Li (2001) indicated that the degree of soil desiccation was closely related to the type, density, growth years and root characteristics of planted forests (Ren et al. 2010; Xu et al. 2003). In this study, we confirmed that both precipitation and vegetation had significant influence on soil moisture. However, the influence of precipitation change on soil moisture was slow and gentle, while the influence of planted forests/shrubs on soil moisture was dramatic in the recent decades. Therefore, we believe that the dominant driver of soil desiccation in the Loess Plateau is afforestation. To prevent soil desiccation, the choice of proper restoration way is a major challenge.

Furthermore, although both the grasslands and planted forest/shrub lands had induced soil desiccation compared with the unconverted farmlands, desiccation was much slighter in the grasslands than that in planted forest lands. In the natural grasslands, the vegetation community could keep selfsuccession and sustainable development (Zhu and Huang 1993). In the planted forest/shrub lands, the soil moisture content commonly dropped to the wilt moisture level in deep soil. Self-thinning continually occurred with increasing years under the planted forests, whether in dryer or wetter area. We investigated two planted $R$. pseudoacacia forest lands which had been planted over 40 years. These lands could hardly still be forest lands but grasslands because most of the trees had died. Another problem was that the planted forest/shrub lands were unable to keep healthy self-succession (Hou and Han 2000), and it would be difficult to replant trees or other deeproot plants on the dried land in a long time (Wang et al. 2003; Wang 2007). That was very disadvantageous to the vegetation restoration project in the Loess Plateau.

Due to the intense soil erosion on slope farmland, most of the farmlands had to be re-vegetated in the Loess Plateau (Su et al. 2011). To our knowledge, both natural grassland and planted forest/shrub land had excellent effect on preventing soil erosion (Chen et al. 2008b). In consideration of the soil moisture conservation and the vegetation sustainable development, we suggest that natural grassland is a better choice than planted $R$. pseudoacacia land for ecological recovery, especially in the northern loess zone with low soil moisture, where the planted trees grow poorly and hardly produce any ecological benefit. In 
the central semi-equilibrated zone, such as the Renjiatai catchment, once the farmland was abandoned, it would be recovered by dense grasses in several months and then be replaced by native shrubs or trees (mainly Populus davidiana and Quercus liaotungensis) in several decades which have better ability of self-regulation and long-term survival than planted forests (Wang et al. 2005). Thus, we suggest that in the north-central Loess Plateau, abandoning of slope farmland is a more effective measure for ecological recovery.

\section{Conclusions}

At slope scale, the deep soil moisture $(>100 \mathrm{~cm})$ was rather heterogeneous in the grasslands, while relatively homogeneous in the planted forest/shrub lands. And this phenomenon commonly existed despite the difference of climate, ante-precipitation and terrain properties between the plots. More spatial replicates were necessary in the grassland than in the planted shrub/forest land when investigating the deep soil moisture.

At small catchment scale, the average soil moisture content in $20-400 \mathrm{~cm}$ depth commonly ranked as farmland $>$ natural grassland $>$ planted forest land. This rank of soil moisture between land use types commonly existed in all the catchments, despite the climate difference in each catchment. The restored grass and planted forest had all induced soil desiccation compared with the unconverted farmlands, but the desiccation was much slighter in the grasslands than that in the forest lands. The soil moisture in the planted $R$. pseudoacacia forest lands had generally dropped to wilt point in less than 30 years.

At regional scale, the precipitation was a significant factor to soil moisture according to the correlation analysis. However, the influence of precipitation change on soil moisture would be a slow and gentle process. Comparatively, the afforestation had decreased soil moisture dramatically in less than 30 years, with the decrease reaching $6.9-12.9 \%$ compared with the unconverted farmland. Therefore, we identified that afforestation was the major driver of soil desiccation in the Loess Plateau of China.

Based on an overall consideration of the effect of soil erosion prevention, soil moisture conservation and vegetation sustainable development, we suggested that the abandonment of slope farmland was a better restoration measure in the north-central Loess Plateau.

Acknowledgments We thank Mr. Guangyao Gao, Mr. Yanda Xu and Miss. Dandan Yu for the field assistance. This research was supported by the National Natural Science Foundation of China (No.40930528), State Forestry Administration of China (No. 201004058) and the CAS/ SAFEA International Partnership Program for Creative Research Teams of "Ecosystem Processes and Services."

\section{References}

Ali GA, Roy AG, Legendre P (2010) Spatial relationships between soil moisture patterns and topographic variables at multiple scales in a humid temperate forested catchment. Water Resour Res 46: W10526. doi:10.1029/2009wr008804

Bi HX, Zhang JJ, Zhu JZ, Lin LL, Guo CY, Ren Y, Yun L, Ma N (2008) Spatial dynamics of soil moisture in a complex terrain in the semi-arid Loess Plateau region, China. J Am Water Resour As 44(5):1121-1131

Bi HX, Li XY, Liu X, Guo MX, Li J (2009) A case study of spatial heterogeneity of soil moisture in the Loess Plateau, western China: a geostatistical approach. Int J Sediment Res 24(1):63-73

Brocca L, Melone F, Moramarco T, Morbidelli R (2010) Spatialtemporal variability of soil moisture and its estimation across scales. Water Resour Res 46:1-14

Chen YM, Liu GB, Yang QK (2004) Zonal characteristics of artificial forest effecting soil moisture on Loess Plateau. J Nat Resour 19 (2): $195-200$

Chen LD, Huang ZL, Gong J, Fu BJ, Huang YL (2007) The effect of land cover/vegetation on soil water dynamic in the hilly area of the loess plateau, China. Catena 70(2):200-208

Chen HS, Shao MG, Li YY (2008a) Soil desiccation in the Loess Plateau of China. Geoderma 143(1-2):91-100

Chen J, Liu WZ, Zhang XC (2008b) Soil and water conservation benefits and suitability of different forestation trees in tablelandgully area of the Loess Plateau. J Northwest A \& F Univ (Nat Sci Edn) 36(6):97-112

Das NN, Mohanty BP, Njoku EG (2010) Profile soil moisture across spatial scales under different hydroclimatic conditions. Soil Sci 175(7):315-319

Ersahin S, Brohi AR (2006) Spatial variation of soil water content in topsoil and subsoil of a Typic Ustifluvent. Agr Water Manag 83 $(1-2): 79-86$

Fu BJ, Wang J, Chen LD, Qiu Y (2003) The effects of land use on soil moisture variation in the Danangou catchment of the Loess Plateau, China. Catena 54(1-2):197-213

Fu BJ, Liang D, Lu N (2011) Landscape ecology: coupling of pattern, process, and scale. Chin Geogra Sci 21(4):385-391

Gomez-Plaza A, Martinez-Mena M, Albaladejo J, Castillo VM (2001) Factors regulating spatial distribution of soil water content in small semiarid catchments. J Hydrol 253(1-4):211-226

Grayson RB, Western AW, Chiew FHS, Bloschl G (1997) Preferred states in spatial soil moisture patterns: local and nonlocal controls. Water Resour Res 33(12):2897-2908

Hawley ME, Jackson TJ, Mccuen RH (1983) Surface soil-moisture variation on small agricultural watersheds. J Hydrol 62(1-4):179200

Hou QC, Han RL (2000) Problems on vegetation construction in Loess Plateau region. Bull Soil Water Conserv 20(2):53-56

Ivanov V, Fatichi S, Jenerette G, Espeleta J, Troch P, Huxman T (2010) Hysteresis of soil moisture spatial heterogeneity and the "homogenizing" effect of vegetation. Water Resour Res 46:1-15

Joshi C, Mohanty BP (2010) Physical controls of near-surface soil moisture across varying spatial scales in an agricultural landscape during SMEX02. Water Resour Res 46(w12503): W12503

Li YS (2001) Effects of forest on water circle on the Loess Plateau. J Natural Resour 16(5):427-432

Li YY, Shao MA (2001) Climatic change, vegetation evolution and low moisture layer of soil on the Loess Plateau. J Arid Land Resour Environ 15(1):72-77

Li XY, Bi HX, Li J, Liu X, Guo MX (2006) Dynamics of moisture of soil profile in Loess area of western Shanxi. Sci Soil Water Conserv 4(4):72-77 
Li Z, Liu WZ, Zhang XC (2009) Assessing the impact of climate change on soil water balance in the Loess Plateau of China. Adv Inf Commun Technol 294:871-880

Liu W, Zhang XC, Dang T, Zhu O, Li Z, Wang J, Wang R, Gao C (2010) Soil water dynamics and deep soil recharge in a record wet year in the southern Loess Plateau of China. Agr Water Manage 97(8, Sp. Iss. SI):1133-1138

Lu AG (2009) Spatial and temporal precipitation variation on the Loess Plateau in the past half century. Ecol Environ Sci 18(3):957-959

McLaren JR, Wilson SD, Peltzer DA (2001) Plant growth-form effects on the spatial and temporal heterogeneity of soil moisture. Ecological Society of America Annual Meeting Abstracts 86:155

Miyamoto T, Putiso M, Shiono T, Taruya H, Chikushi J (2003) Spatial and temporal distribution of soil water content in fields under different vegetation conditions based on TDR measurements. Jarq - Jpnagr Res Q 37(4):243-248

Mohanty BP, Das NN, Cosh MH, Jackson TJ (2008) Modeling and assimilation of root zone soil moisture using remote sensing observations in Walnut Gulch Watershed during SMEX04. Remote Sens Environ 112(2):415-429

Qiu Y, Fu BJ, Wang J, Chen LD (2001) Soil moisture variation in relation to topography and land use in a hillslope catchment of the Loess Plateau, China. J Hydrol 240(3-4):243-263

Qiu Y, Fu B, Wang J, Chen L, Meng Q, Zhang Y (2010) Spatial prediction of soil moisture content using multiple-linear regressions in a gully catchment of the Loess Plateau, China. J Arid Environ 74 (2):208-220

Ramos MC, Mulligan M (2005) Spatial modelling of the impact of climate variability on the annual soil moisture regime in a mechanized Mediterranean vineyard. J Hydrol 306(1-4):287-301

Ren XL, Jia ZK, Wan SM, Chen XL (2010) Soil water distribution on different number of growing years of alfalfa pasture in the Loess Plateau of Northwest China. Afr J Biotechnol 9(35):5686-5693

Shangguan ZP (2007) Soil desiccation occurrence and its impact on forest vegetation in the Loess Plateau of China. Int J Sus Dev World 14(3):299-306

Su CH, Fu BJ, Lu YH, Lu N, Zeng Y, He AN, Lamparski H (2011) Land use change and anthropogenic driving forces: a case study in Yanhe River Basin. Chin Geogra Sci 21(5):587-599

Teuling AJ, Hupet F, Uijlenhoet R, Troch PA (2007) Climate variability effects on spatial soil moisture dynamics. Geophys Res Lett 34 (6): L06406

Timm LC, Pires LF, Roveratti R, Arthur RCJ, Reichardt K, de Oliveira JCM, Bacchi OOS (2006) Field spatial and temporal patterns of soil water content and bulk density changes. Sci Agric 63(1):55-64

Vivoni ER, Gutierrez-Jurado HA, Aragon CA, Mendez-Barroso LA, Rinehart AJ, Wyckoff RL, Rodriguez JC, Watts CJ, Bolten JD, Lakshmi V, Jackson TJ (2007) Variation of hydrometeorological conditions along a topographic transect in northwestern Mexico during the North American monsoon. J Climate 20(9):1792-1809

Wang HS (2007) Discussion on feedback effect of soil desiccation by vegetation and related issues. Prog Geogr 26(6):33-39

Wang J, Fu BJ, Qiu Y, Chen LD, Wang Z (2001) Geostatistical analysis of soil moisture variability on Da Nangou catchment of the loess plateau, China. Environ Geol 41(1-2):113-120

Wang ZQ, Liu BY, Lu BJ (2003) A study on water restoration of dry soil layers in the semi-arid area of Loess Plateau. Acta Ecologica Sinica 23(9):1944-1950
Wang L, Shao MA, Zhang QF (2004) Distribution and characters of soil dry layer in north Shaanxi Loess Plateau. Chin J Appl Ecol 15 (3):436-442

Wang L, Shao MA, Wang QJ (2005) Comparison of soil desiccations in natural and acacia forests in the Ziwuling Mountain of the Loess Plateau. Acta Bot Bor-Occ Sinica 25(7):1279-1286

Wang L, Wang QJ, Wei SP, Shao MA, Yi L (2008) Soil desiccation for Loess soils on natural and regrown areas. Forest Ecol Manage 255 (7):2467-2477

Wang ZQ, Liu BY, Liu G, Zhang YX (2009a) Soil water depletion depth by planted vegetation on the Loess Plateau. Sci China Ser D-Earth Sci 52(6):835-842

Wang ZQ, Liu BY, Zhang Y (2009b) Soil moisture of different vegetation types on the Loess Plateau. J Geogr Sci 19(6):707-718

Wang YQ, Shao MA, Liu ZP (2010a) Large-scale spatial variability of dried soil layers and related factors across the entire Loess Plateau of China. Geoderma 159(1-2):99-108

Wang YQ, Shao MA, Shao HB (2010b) A preliminary investigation of the dynamic characteristics of dried soil layers on the Loess Plateau of China. J Hydrol 381(1-2):9-17

Wang YQ, Shao MA, Zhu YJ, Liu ZP (2011) Impacts of land use and plant characteristics on dried soil layers in different climatic regions on the Loess Plateau of China. Agr Forest Meteorol 151 (4):437-448

Western AW, Grayson RB, Bloschl G, Willgoose GR, McMahon TA (1999) Observed spatial organization of soil moisture and its relation to terrain indices. Water Resour Res 35(3):797-810

Xu XX, Liu JH, Gao P (2003) A study on the effect of soil moisture of different vegetations in Loess Hilly Region. Acta Bot Bor-Occ Sin 23(8): 1347-1351

Yang WZ, Ma YX, Han SF (1994) Soil water ecological regionalization of afforestation in Loess Plateau. J Soil Water Conserv 8 (1): $1-9$

Yang WZ, Shao MA, Peng XD, Xia WS (1999) On the relationship between environmental aridization of the Loess Plateau and soil water in loess. Sci China Ser D-Earth Sci 42(3):240-249

Yeh PJF, Eltahir EAB (1998) Stochastic analysis of the relationship between topography and the spatial distribution of soil moisture. Water Resour Res 34(8):2075-2075

Yun L, Bi HX, Tian XL (2010) Research on spatial heterogeneity of soil moisture after raining at forest-grassland boundary in the Loess region of west Shanxi. Ecol Environ Sci 19(4):938-944

Zeng C, Shao MA, Wang QJ, Zhang J (2011) Effects of land use on temporal-spatial variability of soil water and soil-water conservation. Acta Agr Scand B-S P 61(1):1-13

Zhao PP, Shao MA (2010) Soil water spatial distribution in dam farmland on the Loess Plateau, China. Acta Agr Scand B-S P 60 (2): $117-125$

Zhu ZC, Huang K (1993) Recovering succession of vegetation on Forest Steppe Zone of Loess Plateau in North Shaanxi Province. J Shanxi Univ (Nat Sci Edn) 16(1):94-100

Zhu XA, Li YS, Peng XA, Zhang SG (1983) Soils of the Loess Region in China. Geoderma 29(3):237-255

Zribi M, Le Hetarat-Mascle S, Ottle C, Kammoun B, Guerin C (2003) Surface soil moisture estimation from the synergistic use of the (multi-incidence and multi-resolution) active microwave ERS Wind Scatterometer and SAR data. Remote Sens Environ 86 (1):30-41 